ship which is demanded by an age of rapid technological change. Even if judgment cannot be taught, it can at least be fostered, and the immense social importance of sound judgment would in itself justify every effort to encourage its development were it not also true that in fact certain university courses are already noted for their capacity to develop judgment, as well as the vision and understanding that the manager and administrator need in increasing measure to-day.

\section{HOMINIDS AND 'HUMANS'}

The Osteodontokeratic Culture of Australopithecus prometheus

By Prof. Raymond A. Dart. (Transvaal Museum Memoir, No. 10.) Pp. viii + 105. (Pretoria: Transvaal Museum, 1957.) n.p.

VER the past thirty years the fossil Australopithecinae from the Early Pleistocene of South Africa, because of their remarkably primitive characters, have naturally provoked a good deal of discussion. The continued accession of much more complete skeletal material from limestone deposits in the Transvaal, however, has served to dispel earlier doubts which had been expressed about their taxonomic position, and the general consensus of opinion to-day has been fairly represented by the American palæontologist, Dr. G. G. Simpson, in a recent article (Science, April 26, 1957) in which he expresses the opinion that "the accumulated evidence is now overwhelmingly in favour of hominid affinities". But while the australopithecines may be accepted as early representatives of the family Hominidae, it does not necessarily follow that such terms as 'human' or 'man' can properly be applied to them. It is important to emphasize this distinction, for much confusion has unhappily been introduced into discussions on hominid evolution by the careless use of these colloquial terms. If it is agreed that the term 'man' should be reserved for those more advanced stages of hominid evolution characterized by the ability to fabricate tools, it is clearly not applicable to such primitive hominids as the australopithecines unless it can be demonstrated that they were tool makers.

The evidence which has so far been adduced for such a conclusion has either proved to be faulty, or, at the most, no more than suggestive. Prof. Dart, in his monograph on the bone breccia from the australopithecine deposits at Makapan, insists that it is much more than suggestive, for he claims that the rich assortment of animal remains from this breccia bears witness to an elaborate bone culture. But it is one thing to show, as Dart endeavours to do, that these fragments of bones and jaws could have been used as tools and weapons, and quite another thing to prove that they were used as such. Without doubt, Dart goes far beyond the legitimate limits of his evidence in propounding these claims, and it is a pity that this should be so, for his undue emphasis on this aspect of his studies obscures the more important parts of his monograph. It is unfortunate, also, that this over-emphatic style of writing must inevitably prejudice the reader against some of his quite legitimate inferences. The latter are concerned with the general nature and composition of the bone breccia. In the first place, Dart casts serious doubt on the suggestion that the accumulation of animal bones could have resulted from the activities of hyænas in occupation of the Makapan caves, or that they were carried in by porcupines. Here his argument is based on observations on the natural habits of these creatures to-day-there is no good evidence that they ever accumulate bony fragments of the kind, or in the number, found in the Makapan breccia.

Could the latter then be the relics of the hunting activities of the australopithecines? This is Dart's contention, and he seeks to test his conclusions by a most interesting analysis of the composition of the bone breccia in terms of the comparative frequencies of different skeletal elements of different animals. For example, he finds that 92 per cent of the total fragments recovered are those of Bovidae, and of 163 vertebral fragments of these animals 56 per cent are cervical vertebrae (as against 44 per cent of the thoraco-lumbo-sacral series). Moreover, about half the cervical vertebrae are the first and second (atlases and axes). From such data he infers that the bovid heads with a few of the adjacent cervical vertebrae must have been severed from the body before being carried off to the cave. Again, he finds great discrepancies numerically in the limb fragments-for example, 336 humeri as compared with 56 femoraand argues that this implies a selection of limb parts for the use which could be made of the bones as weapons. The quantities of bone flakes, many of them sharply pointed, he attributes to deliberate and systematic manufacture for use as flake tools, if only because there does not appear to be any other ready explanation for them.

Similar interpretations based on similar bone deposits have been put forward on previous occasions by archæologists. For example, Abbé Breuil, writing in the Bulletin of the Geological Society of China in 1931, supposed the bone flakes found in association with the remains of Pekin man at Choukoutien to be evidence of a bone-flake culture. In this case, however, some critics suggested that, before accepting such a conclusion, it would be well to examine bone breccias formed under conditions which would exclude all possibility of human ageney, and no doubt the same criticism might be advanced in reference to Dart's conclusions. But if Dart, in pointing the way to the study of bone breccias by a statistical analysis of their composition, stimulates comparable studies on an extensive scale, his monograph will have served a most useful and important purpose. It may be, indeed, that the results of such comparisons will add support to his contentions that the australopithecines were sufficiently advanced to have established a veritable bone culture. For the moment, however, such a claim is surely premature.

W. E. Le Gros Clark

\section{THE NEW PHYSICS}

\section{An Approach to Modern Physics}

By Prof. E. N. da C. Andrade. Pp. ix $+232+16$ plates. (London: G. Bell and Sons, Ltd., 1956.) 25s. net.

DHYSTCS has advanced a long way since Andrade's book, "The Mechanism of Nature", first appeared in 1930. Then was a time of rapid advance, based on the new fundamental principles of the quantum theory, which had become sufficiently clarified in 1925 to bring order into much that had been chaotic. Now is a time of scarcely less rapid advance, relying 